Article

\title{
Efficacy of Indigenously Prepared Sugarcane and Pineapple Wine Solvents for Washing Highly Dioxin-Contaminated Field Soils
}

\author{
Chi Thanh $\mathrm{Vu}^{3,+}{ }^{10}$, Huu Tuan Tran ${ }^{1,+}{ }^{\text {, Acharee Kaewlaoyoong }}{ }^{1,2}$, Wen-Yen Huang ${ }^{1}$ and \\ Chitsan Lin ${ }^{1, *}$ \\ 1 Institute of Marine Science and Technology, National Kaohsiung University of Science and Technology, \\ Kaohsiung 81157, Taiwan; huutuan.tnx@gmail.com (H.T.T.); HLKUO0121@gmail.com (W.-Y.H.) \\ 2 Department of Safety, Health and Environmental Engineering, National Kaohsiung University of Science \\ and Technology, Kaohsiung 82445, Taiwan; meen-ak@hotmail.com \\ 3 Civil and Environmental Engineering Department, The University of Alabama in Huntsville, \\ Huntsville, AL 35899, USA; tv0009@uah.edu \\ * Correspondence: ctlin@nkust.edu.tw; Tel: +886-7-3651472; Fax: +886-7-3651472 \\ + These authors contributed equally to this work.
}

Received: 17 November 2018; Accepted: 20 December 2018; Published: 25 December 2018

Featured Application: This paper dealt with high concentrations of PCDD/Fs in soil by washing with winery solvents, which are believed to be more environmentally benign than chemical surfactants.

\begin{abstract}
Poly-chlorinated dibenzo-p-dioxins (PCDDs) and poly-chlorinated dibenzo-furans (PCDFs) negatively affect human health and are often found as unwanted by-products of chemical handling and manufacture procedures. While commercial solvents have been used to remove dioxins from contaminated soil, these solvents themselves may adversely affect soil health. In this study, we examined the effects of washing highly PCDD/F contaminated field-soil with two natural solvents (sugarcane and pineapple wine) under ambient temperature. Performing an initial three-washing-cycle experiment, we found that sugarcane wine more effectively removed the contaminants than pineapple wine (removal, $60 \%$ vs. $50 \%$ ) and chose it to perform a six-washing-cycle experiment facilitated by mechanical stirring and ultrasonication. Sugarcane wine was found to have a high removal efficiency (almost $80 \%$ ), largely due to its higher alcohol and acid content. We believe that both wines can be used in soil remediation tasks without further damage to soil health. This is the first study employing naturally made wines as soil washing solvents in treating highly PCDD/F contaminated field soil. After soil washing processes, the winery solvents are believed to be beneficial to (if necessary) bioremediation methods and/or monitored natural attenuation.
\end{abstract}

Keywords: sugarcane wine; pineapple wine; soil washing; PCDD/Fs; green and sustainable remediation

\section{Introduction}

Dioxins, polychlorinated dibenzo-p-dioxins (PCDDs), and polychlorinated dibenzofurans (PCDFs) negatively affect the environment and human health [1,2]. They are considered nonvolatile chemicals and because of their characteristics of hydrophobicity and lipophilicity, their water-solubility is considerably low, meaning that they are often attached to soil and sediments [3]. Dioxins can accumulate in the food chain and may cause various cancers and mutations. PCDD/Fs have been reported to possibly be associated with sarcomas, lymphomas, chloracne, and other types of cancer and fatalities [4]. Toxic equivalent quantities (TEQs) are often employed to indicate the toxicity of 
dioxin compounds. The TEQ value of 2,3,7,8-TCDD (tetra chlorinated dibenzo dioxin) is designated to be 1.0 and for other congeners, TEQ values are expressed as fractions of the 2,3,7,8-TCDD's value. According to Boening (1998), PCDDs and PCDFs have 75 and 135 possible congeners, respectively. However, only seven PCDD isomers and 10 PCDF isomers are considered as having a dioxin toxicity and assigned TEQ values.

A variety of treatment methods have been proposed for the removal of organic compounds from contaminated soil, such as thermal desorption [5], soil washing [3,6], advanced oxidation processes [7], photodegradation [8], bioremediation [9-11], etc. Among them, soil washing has been considered an effective method taking into account its low treatment cost, particularly when dealing with highly contaminated soil [6]. Several studies have been performed for assessing the capacity of soil washing in remediating different types of contaminants in soil. For example, Huguenot, et al. [12] used a commercial surfactant, Tween ${ }^{\circledR} 80$, to enhance the efficiency of soil washing, which was coupled with an electro-Fenton process in treating soil contaminated with petroleum hydrocarbons. Cao, et al. [13] treated pentachlorophenol contaminated soil by the combination of soil washing with laboratory-made tetrapolyphosphate solvent and zero valent ion (ZVI) / Air treatment.

In soil washing remediation, the power of ultrasonication is often employed with mechanical stirring because its sonophysical effects, which are induced by acoustic cavitation, can enhance the removal of the contaminants [14]. Ultrasound-assisted soil washing was reported to result in better removal efficiencies than the cases where only either mechanical stirring or ultrasonic power was used alone [15]. Ultrasound-assisted soil washing has been employed to treat different types of organic contaminants in soil, e.g., diesel [16] and polycyclic aromatic hydrocarbons (PAHs) [17]. It is reported that the combined effects of macro-scale mixing (mechanical) and micro-scale mixing (ultrasonic) could result in high removal efficiencies [14,16].

Regarding the solvents used in soil washing, various types of solvents, both synthetic and natural, have been studied for different types of contaminated soils [3,18]. Moutsatsou, et al. [19] employed four synthetic solvents, including $\mathrm{HCl}, \mathrm{H}_{2} \mathrm{SO}_{4}, \mathrm{HNO}_{3}$, and $\mathrm{Na}_{2} \mathrm{EDTA}$, for the washing of heavy metals from mining soils. Li, et al. [20] used three types of surfactants (the nonionic: Tween20, Triton X-100; the cationic: CTAB and the anionic: Dodec-MNS, NPS-10) in their petroleum-contaminated soil remediation study. Jonsson, Lind, Lundstedt, Haglund and Tysklind [6] washed different concentrations of PCDD/Fs from aged-soils using ethanol as a solvent. In general, a good solvent should be capable of achieving a high removal efficiency, while being inexpensive and easily used without causing harm to humans and the environment, including soil bio-activity. Chemical solvents are highly effective in the washing of soil contaminated with organic pollutants [21-23], but they also remove micro-organisms, some of which may be beneficial for further bio-attenuation or cultivation $[3,18]$. Wine, being rich in alcohols, might also serve as a healthier alternative bio-surfactant in the removal of dioxins. It might be used to enhance the bio-attenuation ability of soil without dramatically harming the lives of micro-organisms within.

Tainan City, located in southern Taiwan, was once a center for the manufacture of pentachlorophenol (PCP). PCDD/Fs are the unwanted byproducts of PCP manufacturing, which involves processes such as the alkaline hydrolysis of chlorobenzenes and the direct catalytic chlorination of phenols. Although there has been no PCP manufacturing activities in Tainan City since 1989, residual contaminants, including PCDD/Fs, pose a significant threat to human health [24]. In this study, the contaminated field soil was taken from a highly PCDD/F-contaminated site in southern Taiwan. The washing was performed with naturally fermented sugarcane wine or pineapple wine solvents. The removal efficiency of soil washing using the combination of ultrasonic power and mechanical mixing was investigated. 


\section{Materials and Methods}

\subsection{Chemicals}

All solvents used (sulfuric acid, $n$-hexane, methylene chloride and toluene) were analytical or glass distilled grade and purchased from Merck (Darmstadt, Germany). Silica gel (90 g silica gel mixed with $20 \mathrm{~mL}$ sulfuric acid $98.08 \%$ ) and sodium sulphate were purchased from Merck (Darmstadt, Germany) and were activated at $135^{\circ} \mathrm{C}(24 \mathrm{~h})$ and $550{ }^{\circ} \mathrm{C}(48 \mathrm{~h})$, respectively. Potassium hydroxide and sulphuric acid were purchased from VWR International AB (Stockholm, Sweden) and hydrochloric acid from Fisher Chemicals AG (Zurich, Switzerland). Standard solutions were purchased from Sigma-Aldrich (St. Louis, MO, USA). They included 17 dioxin compounds mixed in solvent nonane: 2,3,7,8-TCDD; 2,3,7,8-TCDF; 1,2,3,7,8-PeCDD; 1,2,3,7,8-PeCDF; 2,3,4,7,8-PeCDF; 1,2,3,4,7,8-HxCDD; 1,2,3,6,7,8-HxCDD; 1,2,3,7,8,9-HxCDD; 1,2,3,4,7,8-HxCDF; 1,2,3,6,7,8-HxCDF; 1,2,3,7,8,9-HxCDF; 2,3,4,6,7,8-HxCDF; 1,2,3,4,6,7,8-HpCDD; 1,2,3,4,6,7,8-HpCDF; 1,2,3,4,7,8,9-HpCDF; OCDD; OCDF. Deionized (DI) water was used for all experiments. All other chemicals and reagents were analytical grade.

\subsection{Sugarcane and Pineapple Wine Production}

Sugarcane purchased from a local market was first compressed and filtered to yield the concentrated juice. Then, the juice was boiled at low temperature (approx. $70{ }^{\circ} \mathrm{C}$ ) to sterilize the filtered sugarcane juice. Following this, it was cooled down to room temperature, and the liquid was added with ferment (the ratio is about $3 \mathrm{~g}$ ferment $/ 5 \mathrm{~kg}$ sugarcane liquid) as a traditional treatment of sugarcane wine. The mixture of sugarcane liquid and ferment was then stored in a tightly sealed vessel in a completely dark environment. After 15 days, the liquid was distilled to produce sugarcane wine. The ambient temperature varied between $25^{\circ} \mathrm{C}$ and $30^{\circ} \mathrm{C}$.

Newly ripe pineapples were also collected from a local market and cut into slight slices. Then, they were mixed with rice wine with the ratio of $1 \mathrm{~kg}$ pineapple $/ 2 \mathrm{~L}$ rice wine. The mixture was stored in a porcelain vessel in a completely dark environment. The temperature of the storage varied from $25^{\circ} \mathrm{C}$ to $30^{\circ} \mathrm{C}$.

\subsection{Soil Sample Preparation and Washing Experiments}

The details of soil sample preparation were described in our previous publications [1,2]. Briefly, a soil screening standard of the American Society for Testing and Materials [25] was employed for soil sample preparation. The contaminated soil first taken from a hazardous waste site in Tainan City, South of Taiwan, was manually screened through six different sieving sizes $(2,1,0.5,0.25,0.125,0.053 \mathrm{~mm})$ with water (wet screening) prior to being sun-dried. The soil chosen for the washing experiments in this study was in the range $0.125-0.250 \mathrm{~mm}$ (fine sand) as this accounts for around $70 \%$ of the total mass. It should be noted that the other particle sizes, even the finest ones, could be economically treated by the current treatment method employed at the contaminated site (incineration) considering that the amount of these particles is somewhat small. The dioxin TEQs of the other particle sizes can be viewed from our previous publication [1].

The contaminated soil (100 g) and the liquid wine solvents ( $250 \mathrm{~g})$ were combined in a Teflon-lined $600 \mathrm{~mL}$ Pyrex vessel at a ratio of 1:2.5 (mass basis). The soil and solvent were stirred mechanically by a double-blade propeller powered by a motor (rpm 700) (Figure 1). The vessel was placed in a plate-type ultrasonic cleaner $(200$ Watt, $40 \mathrm{KHz}$, model DC200H, Delta New Instrument Co., Ltd, Taipei, Taiwan). Each washing cycle took sixty minutes under an ultrasonic set temperature of $30^{\circ} \mathrm{C}$ (to represent the ambient temperature in the contaminated site in southern Taiwan). Our washing experiments were performed under the conditions (ambient temperatures and a relatively low agitation-700 rpm) that should be energy-advantageous according to Nakamiya, et al. [26], Meguro, et al. [27] and Jonsson, Lind, Lundstedt, Haglund and Tysklind [6]. After treatment, the particles were allowed to settle 
before the liquid phase was vacuum-filtered through a $110 \mathrm{~nm}$ hydrophilic membrane filter (Millipore, Billerica, MA, USA). A portion of washed soil (10 g-12 g) was used for PCDD/F analysis.

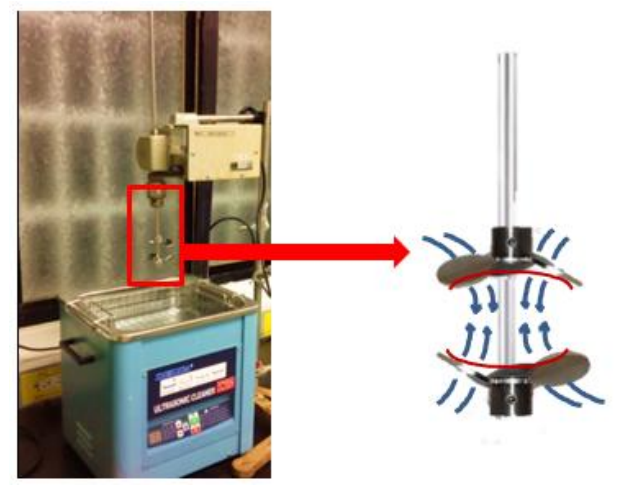

Figure 1. The combination of ultrasonic power and mechanical mixing by double-blade propeller in the washing experiments.

\subsection{Analytical Method}

The details of sample analysis can be viewed in our previous studies [1,2]. Technically, extraction was performed using a method recommended by the United States Environmental Protection Agency [28]. The sample (10 g) was first lyophilized in an Eyela FDU-1200 freeze dryer (Tokyo Rikakikai, Japan). Anhydrous sodium sulfate was then added and mixed before toluene was added for solvent exchange $(40 \mathrm{~mL}$ ). A sonicator (VCX 750, Sonics Materials, Newtown, CT, USA) was used for the extraction in three cycles (approx. $3 \mathrm{~min} / \mathrm{cycle}$ ). The conditions were set at an amplitude of $62 \%$, pulse on was set at 6.0, and pulse off was set at 3.0. The clean-up was performed using another USEPA method [29]. After ultrasonic extraction, sample was processed through a column with three filtering layers: glass wool, acid silica gel $(90 \mathrm{~g}$ silica gel mixed with $20 \mathrm{~mL}$ sulphuric acid $98.08 \%$ ), and anhydrous sodium sulfate. The eluate was evaporated in a Turbo Vap II concentrator (Biotage, Charlotte, NC, USA) using nitrogen (pressure $10 \mathrm{psi}$ ). The concentrate was solvent exchanged with n-hexane $95 \%(50 \mathrm{~mL})$ and then added with acid silica gel before being passed through Whatman ${ }^{\circledR}$ filter paper (pore size $110 \mathrm{~mm}$; manufactured by GE Healthcare UK Limited, Amersham Place, United Kingdom). The final extract was added with sulfuric acid before storage at $-4{ }^{\circ} \mathrm{C}$ until analysis. PCDD/F analysis was performed according to USEPA [30]. A 6890-5973 gas chromatography-mass spectrometry (GC-MS) system with a column HP-5MS $(30 \mathrm{~m} \times 0.25 \mathrm{~mm} \times 0.5 \mu \mathrm{m})$ was used to quantify PCDD/Fs. The oven temperature was set at $40^{\circ} \mathrm{C}$ for four minutes before ramping to $300^{\circ} \mathrm{C}\left(10^{\circ} \mathrm{C} / \mathrm{min}\right)$ for twenty minutes. Selective ion monitoring (SIM) mode was employed according to the retention time and characteristic ions. Concentration calculations and calibrations were based on the standard calibration curve. To efficiently interpret removal efficiencies, PCDD/Fs' concentrations were transformed into TEQs as introduced by the World Health Organization at the Stockholm Convention.

\subsection{Measurement of Bio-Surfactants in Sugarcane Wine and Pineapple Wine Solvents}

As some volatile organic compounds (VOCs) are considered organic solvents [31,32], they may have taken part in the removal of PCDD/Fs in our washing experiment and need to be quantified to better grasp the mechanisms underlying their dioxin removal. Because target compounds were unknown, USEPA method 8260B was adopted for the qualification and quantification of VOCs [33]. In order to clarify the mechanism of the high removal efficiencies of the wine solvents, we spiked them $(10 \mu \mathrm{L}$ each) into a $40 \mathrm{~mL}$ deionized water vial $[1,2]$. Then, using a purge and trap system combined with 6890-5973 GC-MSD for this analysis [33], we compared the peaks we found with those established in the NIST mass spectra library [34]. The concentrations of the compounds were calculated using the concentrations appearing in the automatic report and the known weight of the sample. 


\subsection{Statistical Analysis}

The non-parametric Kruskal Wallis test was employed to analyze the difference in PCDD/F concentrations. The $H$ statistic value was compared with the critical chi-square $\left(\chi_{\mathrm{U}}^{2}\right)$ value $(\alpha=0.05$ was considered significant). Statistical analysis was conducted with IBM SPSS statistics for Windows, Version 22.

\section{Results and Discussion}

\subsection{Preliminary Washings with Sugarcane Wine and Pineapple Wine}

The results of this preliminary washing experiment are shown in Figure 2. The initial total TEQs of the soil is $10024.15 \mathrm{ng}$-TEQ/ $\mathrm{kg}$, which was contributed mostly by OCDF $(5112.51 \mathrm{ng}-\mathrm{TEQ} / \mathrm{kg})$ and 1,2,3,4,6,7,8-HpCDF (3865.65 ng-TEQ/ $\mathrm{kg}$ ), while the TEQ concentration of OCDD was only $1046.00 \mathrm{ng}$-TEQ $/ \mathrm{kg}$. After the third wash, sugarcane wine washing resulted in $60.7 \%$ total TEQ removal, decreasing from $10024.15 \mathrm{ng}-\mathrm{TEQ} / \mathrm{kg}$ to only $3938.74 \mathrm{ng}-\mathrm{TEQ} / \mathrm{kg}$, while the experiment with pineapple wine achieved only 50.2\%, finishing at $4991.33 \mathrm{ng}-\mathrm{TEQ} / \mathrm{kg}$. After the last wash, the soil in the washing experiment with sugarcane wine contained approximate TEQ concentrations of OCDF (1586.62 ng-TEQ/kg) and 1,2,3,4,6,7,8-HpCDF (1824.73 ng-TEQ/kg). Similarly, the last washing in the experiment with pineapple wine also led to the soil being mostly occupied by OCDF (1985.16 ng-TEQ/kg) and 1,2,3,4,6,7,8-HpCDF (2329.11 ng-TEQ/kg). The removal efficiencies for each congener in the sugarcane wine washing were better than those of the pineapple wine washing, e.g., $1,2,3,4,6,7,8-\mathrm{HpCDF}(52.8 \%$ versus $39.8 \%)$ and $\mathrm{OCDD}(49.6 \%$ versus $35.3 \%)\left(\mathrm{H}\right.$ value $\left.>\chi_{\mathrm{U}}^{2}\right)$. The difference between the highest $(69 \%)$ and lowest $(49.6 \%)$ removal efficiencies in the sugarcane wine washing experiment was $19.4 \%$, which was lower than that in the pineapple wine washing experiment $(25.9 \%)$, indicating that sugarcane wine washing might be more non-selective than pineapple wine washing and that sugarcane wine washing might at the same time reduce different PCDD/F congeners. As sugarcane wine proved to be the better solvent of the two, it was chosen for a later experiment determining its capacity to reach a higher removal efficiency after six washing cycles.

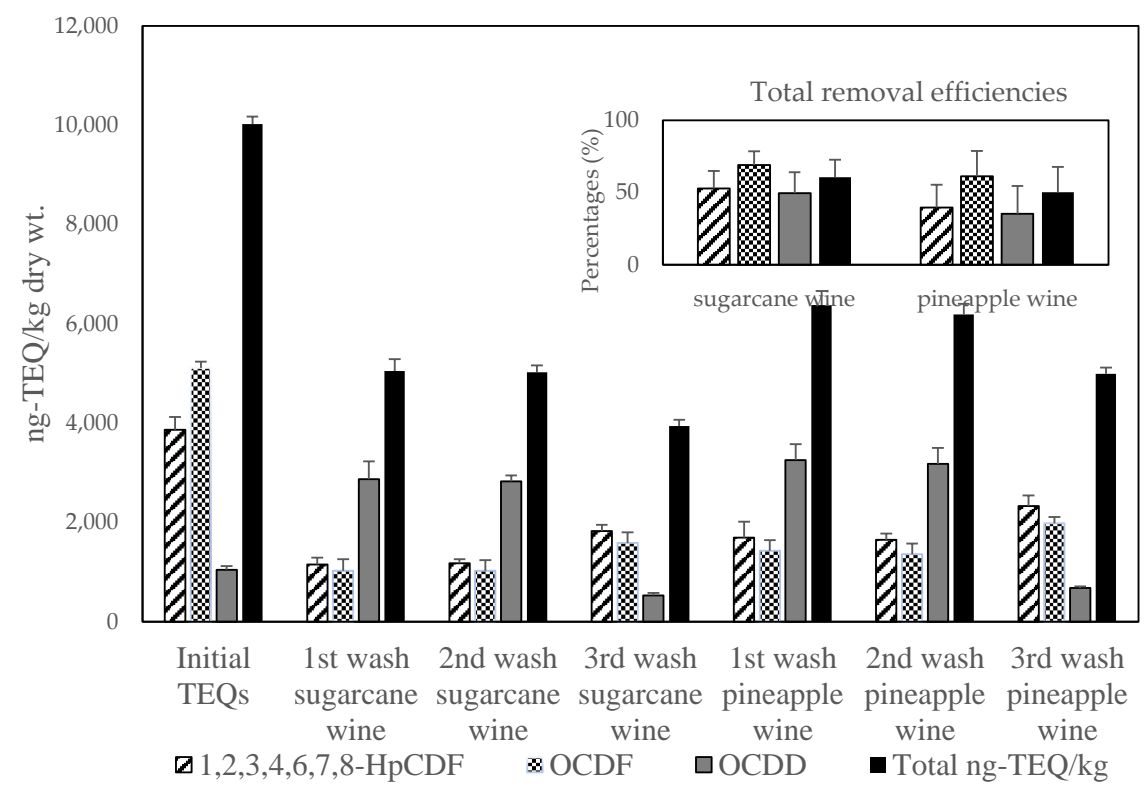

Figure 2. Changes in dioxin toxic equivalent quantities (ng-TEQ/kg dry wt.) and final removal percentages in a preliminary three-cycle soil washing experiment using both sugarcane wine and pineapple wine solvents (HpCDF: Hepta-chlorinated dibenzo-p-furans; OCDF: Octa-chlorinated dibenzo-p-furans; OCDD: Octa-chlorinated dibenzo-p- dioxins). 


\subsection{Extended Sugarcane Wine Washing}

In the next experiment, the soil mostly contained the following dioxin compounds: 1,2,3,4,6,7,8-HpCDF; 1,2,3,4,6,7,8-HpCDD; OCDF; and OCDD (Figure 3). We also conducted a control washing experiment with DI water to clarify the removal efficiency of the wine solvent (Figure 4). The initial total TEQ value of the contaminated soil was $8902.33 \mathrm{ng}-\mathrm{TEQ} / \mathrm{kg}$, which was mainly occupied by OCDD (3853.12 ng-TEQ/kg) and 1,2,3,4,6,7,8-HpCDF (2519.65 ng-TEQ/kg). The removal efficiency of sugarcane wine washing was clearly positive, finishing at a total of $78.7 \%$ removal, which was almost three times higher than the removal efficiency of the control washing experiment with DI water $(28.08 \%)\left(\mathrm{H}\right.$ value $\left.>\chi_{\mathrm{U}}^{2}\right)$. The washed soil of the sugarcane wine washing experiment was also mostly occupied by OCDD (571.36 ng-TEQ/kg) and 1,2,3,4,6,7,8-HpCDF (805.44 ng-TEQ/kg). The removal efficiencies of the sugarcane wine washing experiment for each congener involved were 1,2,3,4,6,7,8-HpCDF (72.0\%), 1,2,3,4,6,7,8-HpCDD (75.5\%), OCDF (75.1\%), and OCDD (85.2\%). The removal efficiencies of the control washing experiment were 1,2,3,4,6,7,8-HpCDF (35.67\%), $1,2,3,4,6,7,8-\mathrm{HpCDD}(46.15 \%)$, OCDF (33.94\%), and OCDD (15.55\%). It seems that different from other studies $[6,26,27]$, our washing experiment with sugarcane wine as a solvent seemed to result in almost no distinct selective removal of dioxin congeners as the removal percentages of different congeners were not much different, which again indicates the non-selectivity washing potential of sugarcane wine. Although the highest and lowest removal percentages were $85.2 \%$ (OCDD) and $72.0 \%(1,2,3,4,6,7,8-\mathrm{HpCDF})$, it should be noted that we conducted our washing experiment on contaminated field soil, of which the characteristics may greatly vary and considerably affect the removal efficiency $[3,6]$. Therefore, our results of sugarcane washing seemed to display more nonselective removal.

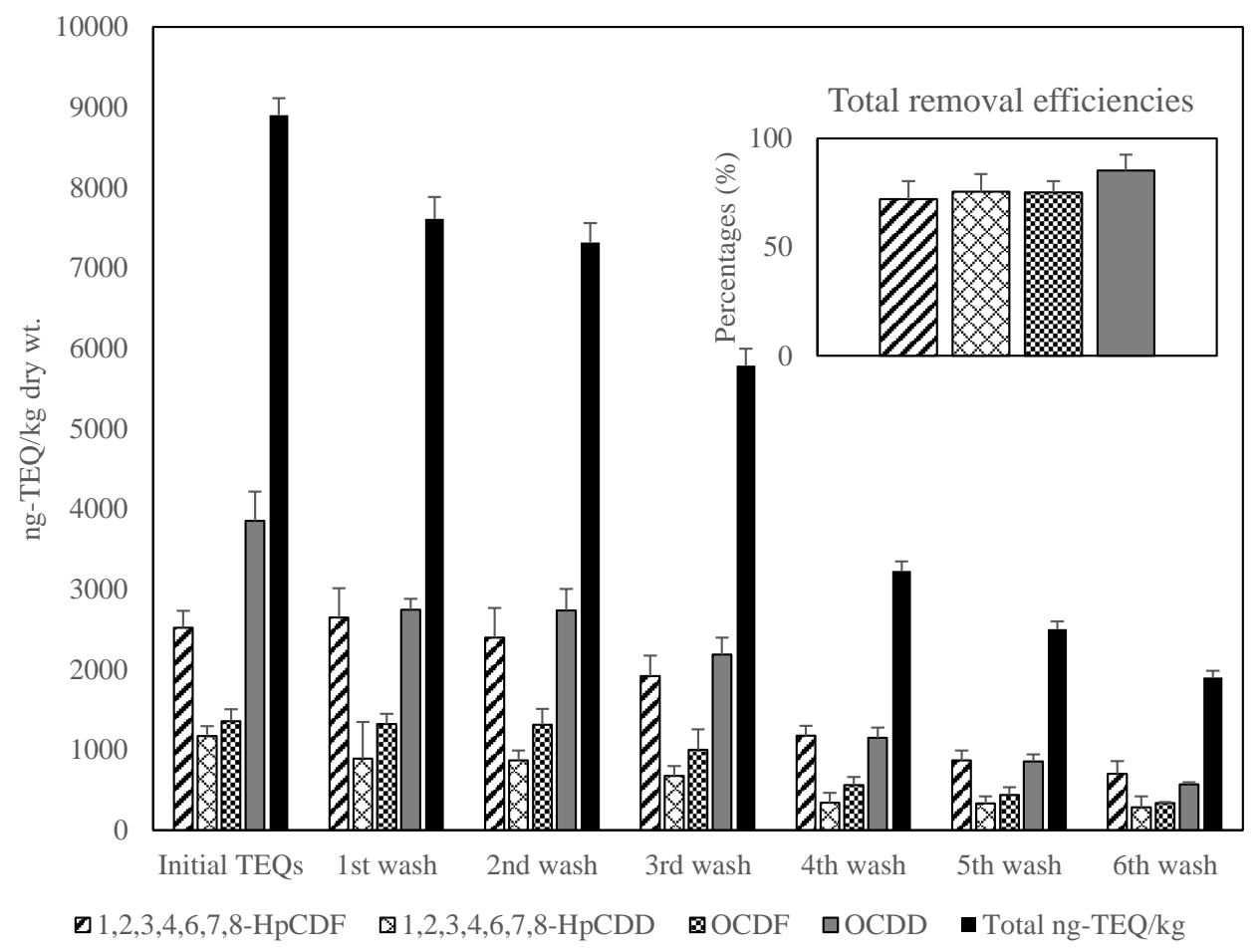

Figure 3. Changes in dioxin toxic equivalent quantities (ng-TEQ/kg dry wt.) and final removal percentages in a soil six-cycle washing experiment using sugarcane wine as the major solvent (HpCDD: Hepta-chlorinated dibenzo-p-dioxins). 


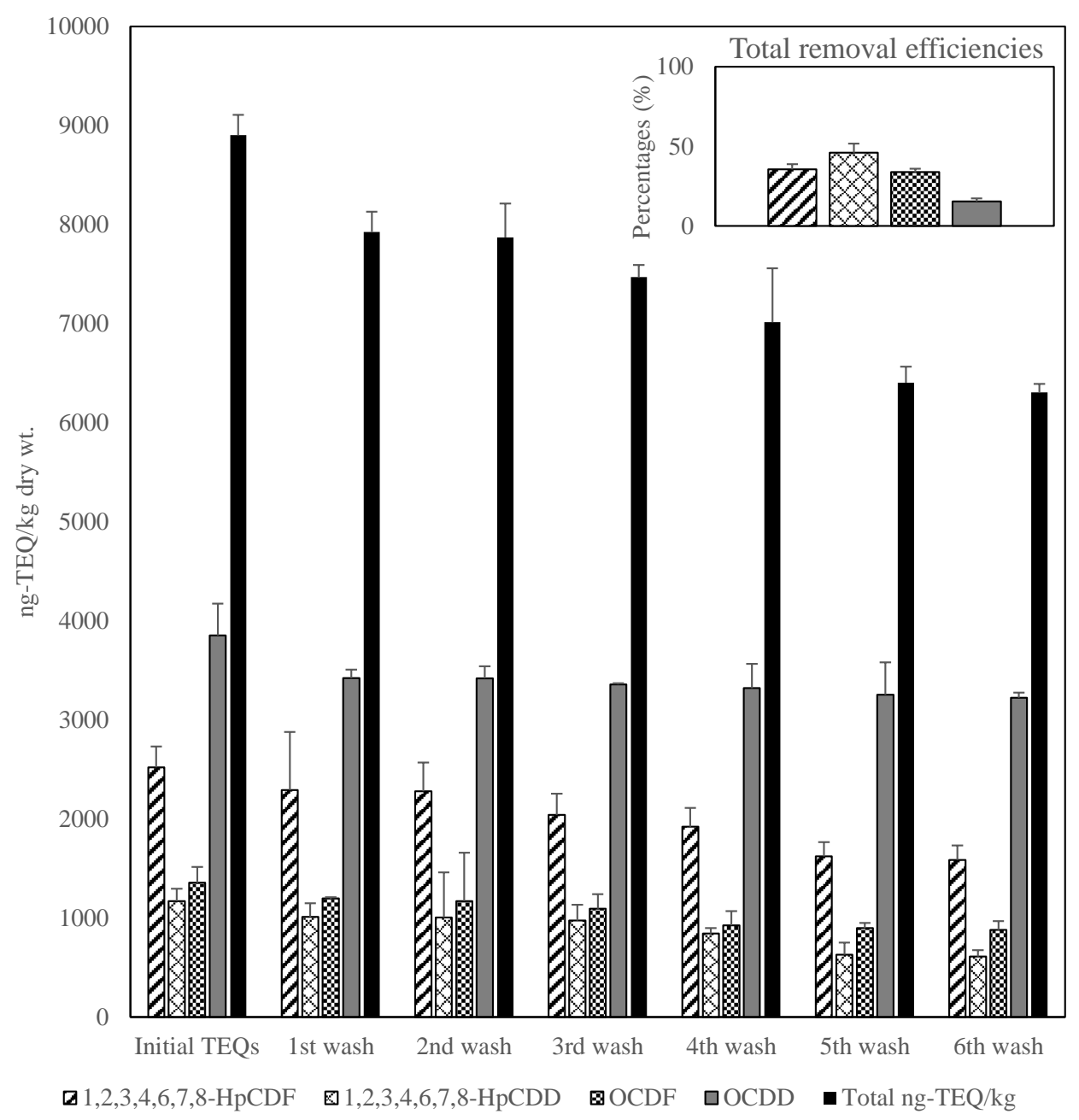

Figure 4. Changes in dioxin toxic equivalent quantities (ng-TEQ/kg dry wt.) and final removal percentages in a soil six-cycle washing experiment using deionized (DI) water.

\subsection{Proposed Mechanisms of PCDD/F Soil Washing}

\subsubsection{Mechanical Stirring and Ultrasonication}

There were two physical processes affecting the tested soil washing experiments-mechanical stirring and ultrasonication (Figure 1). Mechanical stirring is the cause of macro-scale mixing, which may facilitate the desorption of the contaminants from the surface of the soil $[16,35]$. Ultrasonication, meanwhile, induces micro-scale mixing, which may then facilitate the desorption of the contaminants from either the soil surface or the pores $[14,36]$. Additionally, it has been reported that it is less likely for the efficient particle-surface-damaging effect of ultrasonication to reach the inner region of the soil matrix, which could be attributed to large attenuation [14]. In other words, ultrasonication alone can only affect the contaminants on the soil particle surface. Therefore, for the contaminants residing deep inside the soil particles, ultrasonication alone cannot have a strong removing effect since its power is largely reduced (attenuated). To test this hypothesis, we conducted a set of washing experiments with DI water and the results are shown in Figure 5. From Figure 5, it can be clearly seen that the effect of ultrasonic power alone is far less effective than the effect of mechanical stirring $\left(\mathrm{H}\right.$ value $\left.>\chi_{\mathrm{U}}^{2}\right)$, probably because ultrasonic power is unable to reach the inner areas of the soil particles without the macro-scale mixing effect of mechanical stirring. Further, the results of our sequential washings (ultrasonic power followed by mechanical stirring and vice versa) were similar to those of only mechanical stirring $\left(\mathrm{H}\right.$ value $<\chi_{\mathrm{U}}^{2}$ ) and lower than those of the combined mechanical 
stirring and ultrasonic power $\left(\mathrm{H}\right.$ value $>\chi_{\mathrm{U}}^{2}$ ), indicating that either the micro-scale mixing effect of ultrasonication followed by the macro-scale dispersing effect of mechanical stirring or the dispersing effect of mechanical stirring followed by the particle-surface-damaging effect of ultrasonic power is not as effective as the combined forces of both. As mechanical stirring helps to maintain stable slurry conditions (or the suspension of solid particles in the liquid), the micro-scale mixing effect of the ultrasonication can easily reach the contaminants residing deep inside the soil particles [16]. Therefore, in this study, the combination of both mechanical stirring and ultrasonication would be the combination of dispersing and surface-damaging effects, helping the soil washing process achieve its potentially highest efficiencies.

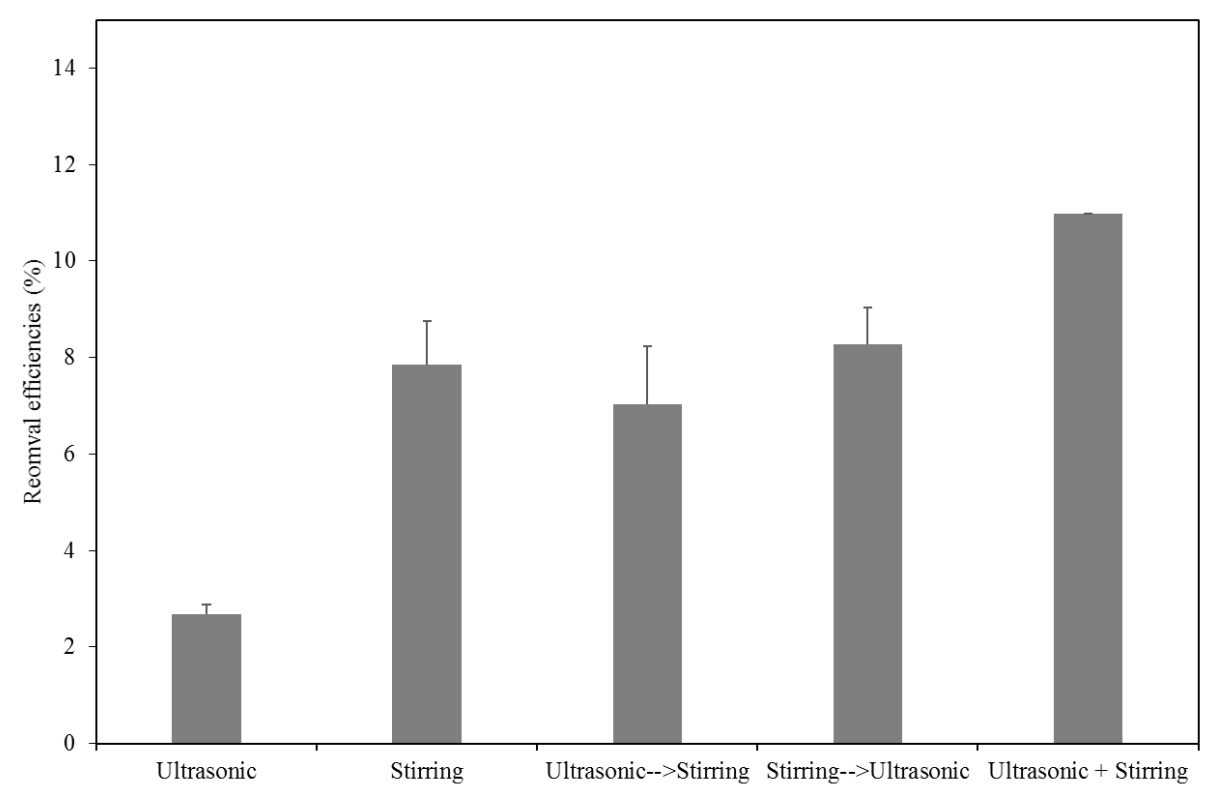

Figure 5. Effects of different physical mechanisms for the removal of PCDD/Fs from contaminated soil.

The position of the propeller is also important for large and homogenous mechanical stirring. We positioned the propeller close to the bottom of the vessel so that the stirring of the double-blade was able to affect as much space within the vessel as possible. As the liquid level was close to the ridge of the cap, sonication was more likely to reach all particles inside. The double-blade propeller was designed to create a space between the two blades, where the particles collided with each other, resulting in the greater breakage and desorption of PCDD/Fs.

\subsubsection{Bio-Surfactant Extraction}

Nakamiya, Furuichi and Ishii [26] compared four commercial solvents, e.g., ethanol, methanol, acetone, and Triton X-100, in removing dioxins from contaminated soil (initial TEQ value $10,000 \mathrm{ng}-\mathrm{TEQ} / \mathrm{kg}$ ) by only mechanical mixing (3000 rpm at room temperature) and concluded that ethanol washing resulted in the highest removal efficiency of $76 \%$ (soil: solvent ratio $10 \%, 10 \mathrm{~min}$ ). Since that study, ethanol has been considered a very effective solvent for removing dioxins in soil. Ethanol was also used as a washing solvent in the study of Meguro, Lee, Nakai and Hosomi [27]. The authors washed dioxin-contaminated soil (9714 ng-TEQ/kg) and sediment (1208 ng-TEQ/ kg) with ethanol $98 \%$ (3 g of soil/sediment with $12 \mathrm{~mL}$ of solvent, $200 \mathrm{rpm}$ at room temperature). After five washes ( 24 hours per wash), the removal efficiencies were very positive, with $89 \%$ for soil and $72 \%$ for sediment. In another study of Jonsson et al. (2010), ten washing times $(20 \mathrm{~g}$ of soil $60 \mathrm{~mL}$ of washing solvent) were used with $75 \%$ ethanol at $60^{\circ} \mathrm{C}$, producing very high removal efficiencies $(81 \%$ to $97 \%$ ). In the current study, the removal efficiencies for sugarcane wine and pineapple wine were slightly lower than the three abovementioned studies, possibly due to the fewer washing cycles used, 
the higher soil: solvent ratio, and the lower ethanol content of these two types of wine. Nevertheless, the idea of using naturally made solvents for soil decontamination is novel, and their benefits in the remediation in soil may outweigh their drawbacks $[3,17]$.

It is reported that commercial ethanol can facilitate the transfer of the contaminants from the soil to the liquid. Its extraction is highly efficient and can be considered for field-scale applications. However, its weakness in this regard is its effect on the bioactivity of the soil. Bio-attenuation and cultivation of soil washed this way is restricted. Therefore, using wine, which has a high fermented alcoholic content, might reduce the possibility of this effect because it also produces a favorable environment for bacteria and fungi growth, which could further facilitate bioremediation methods (if necessary) and/or monitored natural attenuation. The composition of sugarcane wine and pineapple wine solvents was dominated by fermented ethanol in this study (Tables 1 and 2), and thus the relatively high removal efficiency seems understandable. Acidic compounds also affect the solubility of dioxins [37]. The other bio-surfactant compounds, including aldehyde, ketone, and ester, in the wine might also create good conditions for dioxins to be solubilized in the liquid solvent $[1,38]$. Future studies will be needed to characterize the potential effects of limiting and enhancing the bioactivity and bio-toxicity of post-washed soil. In addition, the specific mechanisms underlying of wine's efficiency as a soil-washing solvent and the effects of the wine solvent on the physical and chemical properties of the washed soil also need to be elucidated. Yet, the preliminary results of this study suggest that naturally made solvents possess the ability to replace chemical solvents in washing highly contaminated soils.

Table 1. Identified biosurfactant ingredients from the sugarcane wine.

\begin{tabular}{cccc}
\hline Category & Compounds & Formula & Concentration (mg/L) \\
\hline Alcohol(s) & Ethanol & $\mathrm{C}_{2} \mathrm{H}_{6} \mathrm{O}$ & $3,071.00$ \\
& 1-Propanethiol & $\mathrm{C}_{3} \mathrm{H}_{8} \mathrm{~S}$ & 719.41 \\
Acid(s) & 2-Hexynoic acid & $\mathrm{C}_{6} \mathrm{H}_{9} \mathrm{O}_{2}$ & 435.20 \\
& Boric acid & $\mathrm{H}_{3} \mathrm{BO}_{3}$ & 449.40 \\
& Ethanedioic acid & $\mathrm{C}_{2} \mathrm{H}_{2} \mathrm{O}_{4}$ & 94.90 \\
& Formic acid & $\mathrm{CH}_{2} \mathrm{O}_{2}$ & 72.50 \\
& Propanoic acid & $\mathrm{C}_{3} \mathrm{H}_{6} \mathrm{O}_{2}$ & 103.90 \\
Aldehyde(s) & Acetaldehyde & $\mathrm{C}_{2} \mathrm{H}_{4} \mathrm{O}$ & 182.90 \\
Ketone(s) & 2-Butanone, (2,4-dinitrophenyl) hydrazone & $\mathrm{C}_{10} \mathrm{H}_{12} \mathrm{~N}_{4} \mathrm{O}_{4}$ & 79.40 \\
Ester(s) & Diethyl ester & $\mathrm{C}_{4} \mathrm{H}_{10} \mathrm{O}$ & 94.90 \\
\hline
\end{tabular}

Table 2. Identified biosurfactant ingredients from the pineapple wine.

\begin{tabular}{cccc}
\hline Category & Compounds & Formula & Concentration (mg/L) \\
\hline Alcohol(s) & Ethanol & $\mathrm{C}_{2} \mathrm{H}_{6} \mathrm{O}$ & 1499.20 \\
& Ledene alcohol & $\mathrm{C}_{15} \mathrm{H}_{24} \mathrm{O}$ & 382.00 \\
& 2-Propanol, 1-chloro & $\mathrm{C}_{3} \mathrm{H}_{7} \mathrm{ClO}$ & 485.20 \\
Acid(s) & 2-Pyrazinecarboxylic acid & $\mathrm{C}_{5} \mathrm{H}_{4} \mathrm{~N}_{2} \mathrm{O}_{2}$ & 307.20 \\
& 2-Methylpyrazine-5-carboxylic acid & $\mathrm{C}_{6} \mathrm{H}_{6} \mathrm{~N}_{2} \mathrm{O}_{2}$ & 290.03 \\
& Pyrrolidine-1-thiocarboxylic acid & $\mathrm{C}_{11} \mathrm{H}_{15} \mathrm{~N}_{5}$ & 167.00 \\
& Benzenesulfonic acid & $\mathrm{C}_{7} \mathrm{H}_{7} \mathrm{~N}_{3}$ & 193.00 \\
& 2-Pyrrolidinone & $\mathrm{C}_{4} \mathrm{H}_{5} \mathrm{NO}$ & 363.00 \\
& 2-Amino-4-hydroxypteridine-6-carboxylic acid & $\mathrm{C}_{7} \mathrm{H}_{5} \mathrm{~N}_{5} \mathrm{O}_{3}$ & 172.00 \\
Aldehyde(s) & 1H-Purine-6-sulfonamide & $\mathrm{C}_{5} \mathrm{H}_{5} \mathrm{~N}_{5} \mathrm{O}_{2}$ & 217.60 \\
Ester(s) & 2-ethyl crotonic aldehyde & $\mathrm{C}_{2} \mathrm{H}_{8} \mathrm{O}$ & 253.00 \\
& 2-octynoic acid, methyl ester & $\mathrm{C}_{9} \mathrm{H}_{14} \mathrm{O}_{2}$ & 205.20 \\
& Ethyl acetate & $\mathrm{C}_{4} \mathrm{H}_{8} \mathrm{O}_{2}$ & 210.00 \\
& (2,3-Butadienyloxy)benzene & $\mathrm{C}_{10} \mathrm{H}_{10} \mathrm{O}$ & 218.00 \\
\hline
\end{tabular}

\subsection{Cost Feasibility of Ultrasonic-Assisted Solvent Soil Washing}

This study was performed at a lab-scale level. In larger remediation scales, the energy cost remains a concern. For a volume of between 3500 and 4000 litter, ultrasonic cleaner and industrial stirrer (mixer) 
can cost about 4 and $5 \mathrm{~kW}$ per hour of operation, respectively. Since the electricity unit price in Taiwan is $0.13 \mathrm{USD} / \mathrm{kWh}$, the total electricity cost of washing a volume between 3500 and 4000 litter can be $1.18 \mathrm{USD} / \mathrm{h}$, resulting in a cost of $7.08 \mathrm{USD}$ for six hours (washing cycles). As the electricity cost is minimal, the cost of the soil washing would strongly depend on the solvent.

Tropical Asian countries like Vietnam, Thailand, and Taiwan have a large amount of sugarcane and pineapple farming to provide raw materials for wine and confectionery production. In fact, although there could be some variations between areas and seasons, the price for one litter of sugarcane wine or pineapple wine in those mentioned countries varies between 1 and 8 USD, while the price for industrial-grade ethanol fluctuates from 50 to 100 USD/litter. However, although our study used the newly-made wine, the field-scale remediation taking wine as a washing solvent can take advantage of materials from winery wastes, and leftovers of the wine and confectionery production, which also contain a high amount of alcoholic and other organic biosurfatants [39]. The use of leftovers for soil washing could help reduce the remediation cost. Besides, during the distillation/purification stage of the wine-making process, high molecular-weight volatile organic compounds (SVOCs) were collected and removed as residues although they, together with the light molecular-weight VOCs, may well be beneficial for the washing removal of organic contaminants. Therefore, future applications of sugary/winery leftovers in washing contaminated soil are suggested, using one before the purification stage or one which is less purified so that the heavy alcoholic products are not removed and can contribute to improving the washing efficiency and reducing the overall cost. Additionally, the traditional winery fermentation technique can be applied to ferment recycled food wastes to produce surfactant-rich compost tea for similar soil washing applications, which could improve the removal efficiency (therefore reduce the number of washing cycles) and thus will be covered in our future studies. Studies on the treatment of the washed solvent are also needed as treating the wastewater is always a major concern for soil washing studies. Although this study mainly focuses on the remediation of highly dioxin-contaminated field soil, we suggest biological treatment methods for treating the washed wine solvents since it is believed that the natural wine solvents are bacteria-friendly and can be degraded economically by different biological processes.

\section{Conclusions}

This study evaluated the PCDD/F removal efficiency of soil washing using two natural solvents (sugarcane wine and pineapple wine). The washing experiments were performed under ambient temperatures and a relatively low agitation $(700 \mathrm{rpm})$. Compared to other similar studies, the tested high soil: solvent ratio (1:2.5 by weight) could be cost-advantage considering the lower amount of washed solvent needing to be treated. In a preliminary study, sugarcane wine removed $60 \%$ of the PCDD/Fs after three washes and pineapple wine 50\%, leading us to perform an extended experiment. In the second experiment, sugarcane wine was found to remove around $80 \% \mathrm{PCDD} / \mathrm{F}$ after six washes. This high removal efficiency is attributed to its high ethanol and organic acid content. We conclude that these two wines might be used as washing solvents when remediating field soil highly contaminated with PCDD/Fs. The residual product coming from the manufacture of wine and sugar may be used for this and the washed soil can be backfilled for further monitored natural attenuation or even cultivation.

Author Contributions: Conceptualization, C.L.; Methodology, W.-Y.H.; Formal Analysis, C.T.V. and A.K.; Investigation, C.T.V. and H.T.T.; Resources, W.-Y.H.; Writing-Original Draft Preparation, C.T.V.; Writing-Review \& Editing, C.T.V. and H.T.T.; Visualization, C.T.V. and H.T.T.; Supervision, C.L.; Project Administration, C.L.; Funding Acquisition, W.-Y.H.

Funding: This research received no external funding.

Acknowledgments: The authors thank Ms. Siwalee Yotapukdee for help during the experimental setup, and Ms. Wen-Ming Mao for help during sample analysis.

Conflicts of Interest: The authors declare no conflict of interest. 


\section{References}

1. Hung, W.; Huang, W.-Y.; Lin, C.; Vu, C.T.; Yotapukdee, S.; Kaewlaoyoong, A.; Chen, J.-R.; Shen, Y.-H. The use of ultrasound-assisted anaerobic compost tea washing to remove poly-chlorinated dibenzo-p-dioxins (PCDDs), dibenzo-furans (PCDFs) from highly contaminated field soils. Environ. Sci. Pollut. Res. 2017, 24, 18936-18945. [CrossRef] [PubMed]

2. Vu, C.T.; Lin, C.; Hung, W.; Huang, W.-Y.; Kaewlaoyoong, A.; Yotapukdee, S.; Chen, J.-R.; Shen, Y.-H. Ultrasonic Soil Washing with Fish Oil Extract to Remove Polychlorinated Dibenzo-p-dioxins (PCDDs), Dibenzofurans (PCDFs) from Highly Contaminated Field Soils. Water Air Soil Pollut. 2017, 228, 343. [CrossRef]

3. Trellu, C.; Mousset, E.; Pechaud, Y.; Huguenot, D.; van Hullebusch, E.D.; Esposito, G.; Oturan, M.A. Removal of hydrophobic organic pollutants from soil washing/flushing solutions: A critical review. J. Hazard. Mater. 2016, 306, 149-174. [CrossRef] [PubMed]

4. Mitrou, P.I.; Dimitriadis, G.; Raptis, S.A. Toxic effects of 2,3,7,8-tetrachlorodibenzo-p-dioxin and related compounds. Eur. J. Intern. Med. 2001, 12, 406-411. [CrossRef]

5. Harjanto, S.; Kasai, E.; Terui, T.; Nakamura, T. Behavior of dioxin during thermal remediation in the zone combustion process. Chemosphere 2002, 47, 687-693. [CrossRef]

6. Jonsson, S.; Lind, H.; Lundstedt, S.; Haglund, P.; Tysklind, M. Dioxin removal from contaminated soils by ethanol washing. J. Hazard. Mater. 2010, 179, 393-399. [CrossRef] [PubMed]

7. Vallejo, M.; Roman, M.F.S.; Ortiz, I.; Irabien, A. Overview of the PCDD/Fs degradation potential and formation risk in the application of advanced oxidation processes (AOPs) to wastewater treatment. Chemosphere 2015, 118, 44-56. [CrossRef]

8. Kim, M.K.; O'Keefe, P.W. Photodegradation of polychlorinated dibenzo-p-dioxins and dibenzofurans in aqueous solutions and in organic solvents. Chemosphere 2000, 41, 793-800. [CrossRef]

9. Huang, W.Y.; Hung, W.T.; Vu, C.T.; Chen, W.T.; Lai, J.W.; Lin, C.T. Green and sustainable remediation (GSR) evaluation: Framework, standards, and tool. A case study in Taiwan. Environ. Sci. Pollut. Res. 2016, 23, 21712-21725. [CrossRef]

10. Lin, C.; Kaewlaoyoong, A.; Vu, C.T.; Huang, W.Y. Treatment of Dioxin-Contaminated Soil by Organic Waste Co-composting System. Proceedings of Advanced Materials, Cham, Switzerland, 14 October 2017; pp. 619-623.

11. Tran, H.-T.; Vu, C.-T.; Lin, C.; Bui, X.-T.; Huang, W.-Y.; Vo, T.-D.-H.; Hoang, H.-G.; Liu, W.-Y. Remediation of highly fuel oil-contaminated soil by food waste composting and its volatile organic compound (VOC) emission. Bioresour. Technol. Rep. 2018, 4, 145-152. [CrossRef]

12. Huguenot, D.; Mousset, E.; van Hullebusch, E.D.; Oturan, M.A. Combination of surfactant enhanced soil washing and electro-Fenton process for the treatment of soils contaminated by petroleum hydrocarbons. J. Environ. Manag. 2015, 153, 40-47. [CrossRef] [PubMed]

13. Cao, M.; Wang, L.; Ai, Z.; Zhang, L. Efficient remediation of pentachlorophenol contaminated soil with tetrapolyphosphate washing and subsequent ZVI/Air treatment. J. Hazard. Mater. 2015, 292, 27-33. [CrossRef] [PubMed]

14. Park, B.; Son, Y. Ultrasonic and mechanical soil washing processes for the removal of heavy metals from soils. Ultrason. Sonochem. 2017, 35, 640-645. [CrossRef]

15. Seungmin, N.; Yongwoon, P.; Anna, H.; Jeongsook, H.; Younguk, K.; Jeehyeong, K. Effect of Ultrasound on Surfactant-Aided Soil Washing. Jpn. J. Appl. Phys. 2007, 46, 4775.

16. Son, Y.; Nam, S.; Ashokkumar, M.; Khim, J. Comparison of energy consumptions between ultrasonic, mechanical, and combined soil washing processes. Ultrason. Sonochem. 2012, 19, 395-398. [CrossRef]

17. Chen, F.; Tan, M.; Ma, J.; Li, G.; Qu, J. Restoration of manufactured gas plant site soil through combined ultrasound-assisted soil washing and bioaugmentation. Chemosphere 2016, 146, 289-299. [CrossRef] [PubMed]

18. Laha, S.; Tansel, B.; Ussawarujikulchai, A. Surfactant-soil interactions during surfactant-amended remediation of contaminated soils by hydrophobic organic compounds: A review. J. Environ. Manag. 2009, 90, 95-100. [CrossRef]

19. Moutsatsou, A.; Gregou, M.; Matsas, D.; Protonotarios, V. Washing as a remediation technology applicable in soils heavily polluted by mining-metallurgical activities. Chemosphere 2006, 63, 1632-1640. [CrossRef]

20. Li, G.; Guo, S.; Hu, J. The influence of clay minerals and surfactants on hydrocarbon removal during the washing of petroleum-contaminated soil. Chem. Eng. J. 2016, 286, 191-197. [CrossRef] 
21. Cao, M.; Ye, Y.; Chen, J.; Lu, X. Remediation of arsenic contaminated soil by coupling oxalate washing with subsequent ZVI/Air treatment. Chemosphere 2016, 144, 1313-1318. [CrossRef]

22. Ahn, C.K.; Kim, Y.M.; Woo, S.H.; Park, J.M. Soil washing using various nonionic surfactants and their recovery by selective adsorption with activated carbon. J. Hazard. Mater. 2008, 154, 153-160. [CrossRef]

23. Ye, M.; Sun, M.; Kengara, F.O.; Wang, J.; Ni, N.; Wang, L.; Song, Y.; Yang, X.; Li, H.; Hu, F.; et al. Evaluation of soil washing process with carboxymethyl- $\beta$-cyclodextrin and carboxymethyl chitosan for recovery of PAHs/heavy metals/fluorine from metallurgic plant site. J. Environ. Sci. 2014, 26, 1661-1672. [CrossRef] [PubMed]

24. Lee, C.-C.; Guo, Y.L.; Kuei, C.-H.; Chang, H.-Y.; Hsu, J.-F.; Wang, S.-T.; Liao, P.-C. Human PCDD/PCDF levels near a pentachlorophenol contamination site in Tainan, Taiwan. Chemosphere 2006, 65, 436-448. [CrossRef] [PubMed]

25. ASTM. ASTM E276-13-Standard Test Method for Particle Size or Screen Analysis at No. 4 (4.75-mm) Sieve and Finer for Metal-Bearing Ores and Related Materials; ASTM International: West Conshohocken, PA, USA, 2013.

26. Nakamiya, K.; Furuichi, T.; Ishii, K. Evaluation of the optimal washing conditions for dioxin-contaminated soils from the circumference of an incinerator. J. Mater. Cycles Waste Manag. 2003, 5, 0063-0068. [CrossRef]

27. Meguro, H.; Lee, B.D.; Nakai, S.; Hosomi, M. Evaluation of ethanol washing on dioxins-polluted soil and sediment based on adsorption relationships. Environ. Technol. 2008, 29, 325-332. [CrossRef]

28. United States Environmental Protection Agency (USEPA). Method 3550C-Ultrasonic Extraction; United States Environmental Protection Agency: Washington, DC, USA, 2007.

29. United States Environmental Protection Agency (USEPA). Method 3630C—Silica Gel Cleanup; United States Environmental Protection Agency: Washington, DC, USA, 1996.

30. USEPA. Method 8290A-Polychlorinated Dibenzodioxins (PCDDs) and Polychlorinated Dibenzofurans (PCDFs) by High-Resolution Gas Chromatography/high-Resolution Mass Spectrometry (HRGC/HRMS); United States Environmental Protection Agency: Washington, DC, USA, 1994.

31. Kalkbrenner, A.E.; Schmidt, R.J.; Penlesky, A.C. Environmental Chemical Exposures and Autism Spectrum Disorders: A Review of the Epidemiological Evidence. Curr. Probl. Pediatr. Adolesc. Health Care 2014, 44, 277-318. [CrossRef]

32. Muhammad, F.; Riviere, J.E. Chapter 16-Dermal toxicity A2-GUPTA, RAMESH C. In Veterinary Toxicology; Academic Press: Oxford, UK, 2007; pp. 263-276.

33. United States Environmental Protection Agency (USEPA). Method 8260B-Volatile Organic Compounds by Gas Chromatography/Mass Spectrometry (GC/MS); United States Environmental Protection Agency: Washington, DC, USA, 1996.

34. NIST. NIST Standard Reference Database. NIST/EPA/NIH Mass Spectral Library with Search Program; National Institute of Standards and Technology, US Department of Commerce, Ed.; National Institute of Standards and Technology, US Department of Commerce: Gaithersburg, MD, USA, 2017.

35. Son, Y.; Cha, J.; Lim, M.; Ashokkumar, M.; Khim, J. Comparison of Ultrasonic and Conventional Mechanical Soil-Washing Processes for Diesel-Contaminated Sand. Ind. Eng. Chem. Res. 2011, 50, 2400-2407. [CrossRef]

36. Feng, D.; Aldrich, C. Sonochemical treatment of simulated soil contaminated with diesel. Adv. Environ. Res. 2000, 4, 103-112. [CrossRef]

37. Tanaka, F.; Fukushima, M.; Kikuchi, A.; Yabuta, H.; Ichikawa, H.; Tatsumi, K. Influence of chemical characteristics of humic substances on the partition coefficient of a chlorinated dioxin. Chemosphere 2005, 58, 1319-1326. [CrossRef]

38. Sahle-Demessie, E.; Grosse, D.W.; Bates, E.R. Solvent extraction and soil washing treatment of contaminated soils from wood preserving sites: Bench-scale studies. Remediat. J. 2000, 10, 85-109. [CrossRef]

39. Cardona, C.A.; Quintero, J.A.; Paz, I.C. Production of bioethanol from sugarcane bagasse: Status and perspectives. Bioresour. Technol. 2010, 101, 4754-4766. [CrossRef] [PubMed]

(C) 2018 by the authors. Licensee MDPI, Basel, Switzerland. This article is an open access article distributed under the terms and conditions of the Creative Commons Attribution (CC BY) license (http:/ / creativecommons.org/licenses/by/4.0/). 